\title{
Exploratory and Confirmatory Factor Analysis of Achievement Goals for Indonesian Students in Mathematics Education Programmes
}

\author{
Riyan Hidayat ${ }^{{ }^{*}}$, Sharifah Norul Akmar Syed Zamri ${ }^{1}$, Hutkemri Zulnaidi ${ }^{1}$ \\ ${ }^{1}$ Department of Mathematics and Science Education, Faculty Education, University of Malaya, 50603 Kuala Lumpur, MALAYSIA
}

Received 26 February 2018 - Revised 25 June 2018 • Accepted 6 August 2018

\begin{abstract}
This study examined the validity and reliability of achievement goal instruments to determine the nature of achievement goals for Indonesian students in mathematics education programmes. A total of 538 students participated, selected by using cluster random sampling. A survey design was employed to investigate the factor structure of the achievement goals. Quantitative data were analysed using exploratory factor analysis (EFA) and confirmatory factor analysis (CFA) using SPSS 23 and AMOS 18. EFA revealed similar structures from prior research and the present study. The CFA approach verified the questionnaire of achievement goal was satisfactory for Indonesian students' context. It also confirmed Indonesian students in mathematics education programmes adopt other-avoidance and self-approach goals. This work concludes the achievement goals of Indonesian university students have a six-factor structure. These findings imply the greater importance of validating and confirming the structure of pupils' achievement goals relative to translating a construct into a different language.
\end{abstract}

Keywords: achievement goals, cross-cultural affects, reliability, structural equation modelling, validity

\section{INTRODUCTION}

Achievement goals are increasingly acknowledged as having a vital role in learning outcomes (Lower, Newman, \& Pollard, 2016; Mascret, Elliot, \& Cury, 2015; Wynne, 2014), particularly for solving complex tasks (Maretasani, Masrukan, \& Dwijanto, 2016). Achievement goal theory focuses on the types of goals (purpose or reasons) (Ames, 1992; Pintrich, 2000) that dictate achievement-related behaviours. However, students in higher education hold low achievement goals (Bernardo \& Ismail, 2010; Chen, 2015) to avoid challenges (Pulkka \& Niemivirta, 2015). Prior research also found that such students tend to engage in task-avoidance (David, 2012; Gillet, Lafrenière, Huyghebaert, \& Fouquereau, 2015; Stoeber, Haskew, \& Scott, 2015) and self-avoidance goals (Stoeber et al., 2015) compared to task and self-approach goals. Unfortunately, students who utilise avoidance-oriented methods have negative relationships with academic achievement (Elliot \& McGregor, 2001; Witkow \& Fuligni, 2007). Especially in Indonesian context, students are more likely to employ performance-approach or other-based competence and mastery-avoidance goals (Liem \& Nie, 2008). Avoidance-based goals are based on failure or keeping away from this negative possibility, whereas approach-based goals are based on success and maintaining a positive possibility. Therefore, students who hold other-avoidance goals usually avoid doing worse than their peers, whereas those who have self-approach goals also concentrated on the achievement of self-based competence (i.e., performing better than before).

Interestingly, recent studies have updated the discussion and provided evidence on the validity and reliability issue related to achievement goals in different settings (Brondino, Raccanello, \& Pasini, 2014; David, 2012; Lower \& Turner, 2016; Mascret et al., 2015; Mascret, Elliot, \& Cury, 2017; Méndez-Giménez, Cecchini-Estrada, FernándezRío, Saborit, \& Méndez-Alonso, 2017; Wu, 2012). Clarke (2013) stated that differences in cultural backgrounds are

(C) 2018 by the authors; licensee Modestum Ltd., UK. This article is an open access article distributed under the terms and conditions of the Creative Commons Attribution License (http://creativecommons.org/licenses/by/4.0/).

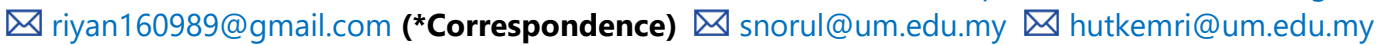




\section{Contribution of this paper to the literature}

- This study contributes towards knowledge on the nature of achievement goals across Indonesian students in mathematics education programmes.

- This study examines the reliability and validity of an achievement goal instrument in the Indonesian context.

- Analysis results revealed that the six-factor correlated model for achievement goals results in acceptable model fit for the Indonesian context. Achievement goals include task-approach goal, task-avoidance goal, self-approach goal, self-avoidance goal, other-approach goal and other-avoidance goal.

becoming progressively noticeable. The present study reveals that the instruments predominantly employed in international comparative research to measure students' achievement goals are prevalently based on those of students from Western cultures (Chamberlin, 2010). For example, after an exploratory factor analysis (EFA) was performed, differences in intercorrelation were either positive (David, 2012) or negative among sub-constructs (Mascret et al., 2015), and differences in structures between countries were found. Surprisingly, Wu (2012) discovered that the $3 \times 2$ achievement goal model resulted in an acceptable model fit for junior high school students in Taiwan, but their elementary school counterparts did not meet the criteria for good fitting models and failed to distinguish between the $3 \times 2$ achievement goals.

Extant literature shows that a comparative research is necessary to examine if the generally accepted instruments for achievement goals are truly universal. Empirical studies have also indicated that the reliabilities of achievement goal instruments differ across countries. The current research aimed to determine the validity and reliability of the achievement goal instrument adopted from Elliot et al. (2011). The universality of affective structures in the Indonesian context was analysed by conducting EFA and confirmatory factor analysis (CFA). At the same time, this work sought to determine the nature of achievement goals for Indonesian students in mathematics education programmes.

\section{Research Questions}

1. Does the six-factor correlated structure of the achievement goal instrument optimally fit data in the Indonesian context?

2. Is the achievement goal instrument reliable and valid for measuring students' goal orientation in the Indonesian context?

3. Do students in mathematics education programmes differ in the six dimensions of achievement goals?

\section{LITERATURE REVIEW}

Achievement goals involve the purposes (Ames, 1992) or cognitive-dynamic manifestations (Elliot \& Church, 1997) of achieving, developing or demonstrating high rather than low ability (Nicholls, 1984). Ames (1992) claims that an achievement goal entails the objectives of achievement behaviour. Similarly, achievement goal theory focuses on the types of goals (purpose or reasons) (Ames, 1992; Maehr \& Zusho, 2009; Pintrich, 2000) that dictate achievement-related behaviours. Achievement goal theorists assume that achievement goals are also broadly connected with a different set of competence-relevant affect, cognition and behaviour (Elliot, 1999). As such, the majority of such theorists concur that an achievement goal refers to purpose. However, in the conceptualisation of achievement goal, purpose is the reason for engaging in achievement behaviour (to develop or demonstrate competence), with the objective pursued while engaging in achievement behaviour (objective/intrapersonal or normative competence) only occasionally involved (Elliot et al., 2011).

Treasure and Roberts (1995) claim that aside from the conception of ability found in students, the cognitive and affective patterns of students are determined by the accepted conception of competency, which affects their beliefs on how to attain success in an activity. Achievement goal theory outlines the idea of students' adaptive and maladaptive responses to achievement challenges (Dweck, 1986; Nicholls, 1984). Adaptive responses are emphasised to encourage the establishment, maintenance and achievement of personally challenging and personally valued achievement goals. By contrast, maladaptive responses are strongly linked to one's failure to produce reasonable, valued goals; preserve effective striving towards those goals; or reach valued goals that are potentially within one's reach (Dweck, 1986).

Achievement goal theory involves different kinds of frameworks (Ames, 1992; Ames \& Archer, 1988; Barron \& Harackiewicz, 2001; Dweck \& Leggett, 1988; Elliot, 1999; Harackiewicz, Barron, \& Elliot, 1998; Midgley, Kaplan, \& Middleton, 2001; Nicholls, 1984; Pintrich, 2000). Researchers and theorists have proposed several frameworks related to achievement goals. For example, the trichotomous framework includes mastery goal, performanceapproach goal, and performance-avoidance goal (Elliot, 1999; Elliot \& Church, 1997; Elliot \& Harackiewicz, 1996). 
A $2 \times 2$ achievement goal framework entails mastery approach, mastery avoidance, performance approach and performance avoidance goals (Elliot \& McGregor, 2001). A 3×2 model of achievement goals is a framework which comprises complex constructs, task approach, task-avoidance, self-approach, self-avoidance, other-approach and other-avoidance (Elliot, Murayama, \& Pekrun, 2011).

Researchers and theorists agree that the main goal of achievement goal theory is classified into two emphases, namely, mastery goals and performance goals (Dweck, 1986; Nicholls, 1984). Mastery goals (adaptive) are represented by challenge seeking and high, effective perseverance amid obstacles. Students who exhibit this pattern usually enjoy the effort in pursuing task mastery. On the contrary, performance goals (maladaptive) are characterised by challenge avoidance and limited perseverance in the face of difficulty. Students who have performance goals tend to indicate negative affect (such as anxiety) and negative self-cognitions when encountering barriers.

\section{3×2 Achievement Goal Framework}

Elliot et al. (2011) propose and examine the latest achievement goal framework known as the $3 \times 2$ system. The proposed framework is developed from the $2 \times 2$ mastery-performance scheme, breaking away from the masteryperformance distinction. For example, according to the $3 \times 2$ framework, mastery-approach and mastery-avoidance goals concentrate on the achievement of task-based or self-based competence and incompetence, respectively, whereas performance-approach and performance-avoidance goals focus on the achievement of other-based competence and incompetence, respectively. The question of interest is whether task-based competence and selfbased competence have similar or diverse goal constructs. Hence, a $3 \times 2$ model of achievement goals (Elliot, Murayama, \& Pekrun, 2011) is the latest framework used in the current study.

Elliot et al. (2011) reveal that task- and self-based goals are integrated under a single concept in which both have an evaluative standard, such as mastery goal. The task-based goal of understanding new course material and the self-based goal of expanding one's knowledge base are obviously closely intertwined. However, task-based and self-based competence will not be appropriate for all situations, and sometimes separating them into two entities is required depending on certain circumstances. Daily life presents many examples related to task-based and selfbased competence. Students working on a crossword puzzle (i.e. task-based goal) may simply be striving to find all of the words in the puzzle but do not care if they enhance their logic abilities (i.e. self-based goal). By contrast, other-based goals constitute a direct analogue of performance goals. Competence in mastery and performance is conceptualised as approach or avoidance. In addition, Elliot et al. (2011) notes the antecedents and consequences of each goal in the $3 \times 2$ framework. However, empirical research on this framework remains lacking in terms of determining associations with other variables, such as achievement, attitudes and metacognitive characteristics.

Mascret et al. (2015) expand the $3 \times 2$ achievement goal framework to the sport domain and conduct two investigations on the development and initial validation of the $3 \times 2$ Achievement Goal Questionnaire for Sport $(3 \times 2$ AGQ-S). The first experiment designs items for the questionnaire and establishes that data from the questionnaire adequately fit the proposed $3 \times 2$ model. The second experiment notes the strong psychometric properties of the measure and links the goal variables to other constructs central to the achievement goal literature. Interestingly, the first study shows a better fit to the $3 \times 2$ framework than to other frameworks and demonstrates that each goal variable has good internal consistency. Conversely, the second study reveals that achievement goals are closely associated with the implicit theories of athletic ability, perceived ability and intrinsic interest variables. Task-based and self-based goals are correlated to mastery-based goals, whereas other-based goals are linked to performancebased goals.

Other empirical data indicate that the distinction between task-based and self-based goals fit well (Mascret et al., 2015; $\mathrm{Wu}, 2012$; Yang et al., 2016) with the $3 \times 2$ achievement goal framework better than with the other three frameworks (dichotomous, trichotomous and $2 \times 2$ achievement goals). Task approach goals are positively associated with audit performance, which deal with failure and interest, whereas self-avoidance goals are negatively linked to dealing with failure (Langer, 2012). Achievement goals also play a pivotal role in online helpseeking but are not significantly related to anxiety (Yang et al., 2016). Furthermore, the $3 \times 2$ framework extends into the individual differences of teachers (Mascret et al., 2017), which are also associated with instructional practices and intrinsic interest (Mascret et al., 2015). However, elementary school students cannot readily distinguish between the $3 \times 2$ achievement goals, which may be caused by their present cognitive ability (Wu, 2012). In the current research, we hypothesise that cultural background contributes towards differences in the correlation and structure of the achievement goals of Indonesian students in mathematics education programmes. 


\section{METHODOLOGY}

\section{Participants and Procedure}

This study follows a survey research design (Cohen, Manion, \& Morrison, 2005; Creswell, 2012; Fitzgerald, Rumrill, \& Schenker, 2004; Fraenkel \& Wallen, 2009). Cross-sectional survey research designs are procedures in quantitative research that provide the opportunity to administer a survey to a sample or to an entire population of people to describe the attitudes, opinions, behaviours or characteristics of the population (Creswell, 2014). The population of the current research consists of students in a mathematics education programme in Indonesia. Given that the present study selects groups rather than individuals, cluster random sampling was suitable (Fraenkel \& Wallen, 2009). The participants comprise 538 students in a mathematics education programme in Riau Province, Indonesia. Female participants were $483(89.8 \%)$, and male participants were 55 (10.2\%). Respondents were from 18 to 22 years old.

The gender disproportion in the departments of the mathematics education programmes resulted in a large proportion of female participants. Targeted students included those from first to fourth year in 2017/2018. However, this research only involved the first, second and third year students because the fourth year students were undergoing their teaching practice sessions. First year students numbered $133(24.7 \%)$, second year participants were $223(41.4 \%)$ and third year students were $182(33.8 \%)$. All selected universities completed the survey during lecture hours which was voluntary. They also completed the questionnaire covering the $3 \times 2$ Achievement Goal Questionnaire.

\section{Measures}

Back translation from the original questionnaire was used in the study to confirm that the translation was precise. A researcher translated the questionnaire from English before the items were used in a pilot study. Then, the items were translated back into Indonesian by three bilingual language experts. The questionnaire used was adopted from Elliot et al. (2011) and consists of six sub-constructs classified into mastery goals (task-approach, taskavoidance, self-approach and self-avoidance goals) and performance goals (other-approach and other-avoidance goals). Each sub-construct has three items, examples of which are provided as follows: task-approach goal (e.g. 'to get a lot of questions right on the exams in this class'), task-avoidance goal (e.g. 'to avoid incorrect answers on the exams in this class'), self-approach goal (e.g. 'to perform better on the exams in this class than I have done in the past on these types of exams'), self-avoidance goal (e.g. 'to avoid doing worse on the exams in this class than I normally do on these types of exams'), other-approach goal (e.g. 'to outperform other students on the exams in this class') and other-avoidance goal (e.g. 'to avoid doing worse than other students on the exams in this class'). The questionnaire consists of 18 questions measured on a seven-point Likert-type scale, which reflect four subconstructs. A seven-point scale ranging from 1 ('strongly disagree') to 7 ('strongly agree') was used in the $3 \times 2$ achievement goals questionnaire (Gillet et al., 2015).

\section{Data Analysis}

Prior to further analysis, the current research also considered numerous issues related to data screening, such as handling missing data, multicollinearity and identification of outliers and normality using the Statistical Package for the Social Sciences (SPSS) 23.0 program. Outliers were identified by a box plot for each sub-construct. For the univariate normality of a construct in a measurement model for a latent variable, the benchmark was that the skewness and kurtosis values for each item were in the range of -1.96 to +1.96 at 0.05 significance level (Hair, Black, Babin, \& Anderson, 2010). Multicollinearity was noted if the correlation matrix with correlations was more than 0.90 (Kline, 2005). Subsequently, data in the present study were analysed in two steps. First, EFA was undertaken to determine the structure of the students' achievement goals. Second, CFA was conducted to investigate whether the established dimensionality and factor-loading pattern fitted the Indonesian context.

EFA was performed using SPSS version 23.0 to explore how many factors are present, whether the factors are correlated and which observed variables appear to best measure every single factor (Schumacker \& Lomax, 2010). This study identified the Kaiser-Meyer-Olkin (KMO) value, Bartlett's value, factor loading, eigenvalue, scree plot and varimax rotation. The KMO index lies between 0 and 1 , with values greater than 0.50 considered appropriate for factor analysis (Chua, 2014), whereas scores over 0.80 were considered highly satisfactory (Frohlich \& Westbrook, 2001). Bartlett's Test of Sphericity was significant ( $\mathrm{p}<0.05)$. For Hair et al. (2010), an overall value of factor loading for each item over 0.50 was significant to confirm the meaningfulness of the questionnaire. Eigenvalue and scree plot also indicated the proportion of variance contribution extracted by each factor through factor analysis (Chua, 2014), where factors with an eigenvalue lower than 1.0 were removed from the factor list. To examine whether the established dimensionality and factor-loading pattern fitted the Indonesian context, CFA 
Table 1. Correlation matrix, means and standard deviations

\begin{tabular}{|c|c|c|c|c|c|c|}
\hline Variable & 1 & 2 & 3 & 4 & 5 & 6 \\
\hline 1. Task-approach goal & 1.000 & $.538^{\star *}$ & $.509^{\star *}$ & $.465^{* *}$ & $.578^{* *}$ & $.476^{* *}$ \\
\hline 2. Self-approach goal & & 1.000 & $.546^{* *}$ & $.585^{* *}$ & $.571^{* *}$ & $.549^{* *}$ \\
\hline 3. Task-avoidance goal & & & 1.000 & $.586^{* *}$ & $.518^{* *}$ & $.559^{* *}$ \\
\hline 4. Self-avoidance goal & & & & 1.000 & $.514^{* *}$ & $.514^{\star *}$ \\
\hline 5. Other-approach goal & & & & & 1.000 & $.561^{\star *}$ \\
\hline 6. Other-avoidance goal & & & & & & 1.000 \\
\hline Skew & -.145 & -1.074 & -.978 & -.904 & -.609 & -1.046 \\
\hline Kurtosis & -.070 & 1.491 & .802 & 1.237 & .087 & 1.225 \\
\hline $\mathrm{M}$ & 4.867 & 5.567 & 5.464 & 5.196 & 5.135 & 5.575 \\
\hline SD & 1.155 & 1.087 & 1.258 & 1.171 & 1.294 & 1.072 \\
\hline
\end{tabular}

Note: **Correlation is significant at the 0.01 level (two-tailed)

using AMOS 18.0 was applied to the second sub-sample. Awang (2012) indicated that goodness of fit was evaluated by employing chi-square $\left(\mathrm{X}^{2}\right)(\mathrm{P}>0.05)$, Comparative Fit Index $(\mathrm{CFI}>0.90)$, Tucker Lewis Index $(\mathrm{TLI}>0.90)$ and Root Mean-Square Error of Approximation (RMSEA < 0.08). Cronbach's alpha coefficients, composite reliability (CR) and average variance extracted (AVE) were calculated to ascertain the reliability of the instrument (both total and sub-constructs) and the split-half correlations. Alpha values in the present study were not expected to be high. According to Hair et al. (2010) alpha values of 0.60-0.70 are satisfactory in exploratory research. At the same time, the CR should be more than 0.60 and AVE should be over 0.50 (Awang, 2012).

\section{RESULTS}

\section{Preliminary Analysis}

The amount of missing data in the current research varied from 0 to $0.5 \%$ per item. Missing data were completely random (MCAR) (Kline, 2005). The means, standard deviations, correlation matrix, skewness and kurtosis for all variables are shown in Table 1.

Results of a preliminary analysis of all the items of task-approach goal, task-avoidance goal, self-approach goal, self-avoidance goal, other-approach goal and other-avoidance goal reached univariate normality (skewness and kurtosis values are in the range of -1.046 to 1.491) (Table 1). In terms of multicollinearity, inter-correlations among the six achievement goals' sub-constructs ranged from 0.465 to 0.586 . Such outcome indicated that the discriminant validities of the variables were reached because the correlation matrix with correlations was lower than 0.90 (Kline, 2005). At the same time, the mean values for achievement goals varied among sub-constructs: task-approach goal $(\mathrm{M}=4.867$ and $\mathrm{SD}=1.155)$, task-avoidance goal $(\mathrm{M}=5.464$ and $\mathrm{SD}=1.258)$, self-approach goal $(\mathrm{M}=5.567$ and $\mathrm{SD}$ $=1.087)$, self-avoidance goal $(\mathrm{M}=5.196$ and $\mathrm{SD}=1.171)$, other-approach goal $(\mathrm{M}=5.135$ and $\mathrm{SD}=1.294)$ and otheravoidance goal $(\mathrm{M}=5.575$ and $\mathrm{SD}=1.072)$.

\section{Exploratory Factor Analysis}

We start the EFA by considering all the 18 items measuring six aspects of achievement goals, namely, taskapproach goal, task-avoidance goal, self-approach goal, self-avoidance goal, other-approach goal and otheravoidance. Each aspect was measured by three items. The statistical criteria in this study were satisfied. The KMO value for achievement goals was $0.923>0.70$, which provided information about the availability of an adequate number of items for each factor. Moreover, the value of Bartlett's Test of Sphericity $\left[\chi^{2}=11611.76 ; p<0.001\right]$ was significant, rejecting the null hypothesis that the correlation matrix was an identity matrix. The next step was to identify the values of the extraction communalities, eigenvalues, percentage of variances and factor loading.

Table 2 presents the detail of factor loading, communalities, eigenvalues and percentage of variances explained by the sub-constructs of achievement goals. Firstly, the values of the extraction communalities represent the variance in each item calculated before and after the factor analysis. The values of such communalities for each item which were less than 0.50 were dropped from further analysis (Hair, Black, Babin, Anderson, \& Tatham, 2006). Small values $(<0.50)$ of the extraction communalities indicate that less than half of the variance in the item was considered in identifying the latent construct. In the current research, all item communalities ranged from 0.832 to 0.959, which exceeded the 0.50 level for adequate explanation. Next, a six-factor solution with eigenvalues over 1 emerged from the EFA, explaining $91.128 \%$ of the variance in total. The goal factors and their contributions were as follows: self-avoidance goal factor, $50.030 \%$; task-avoidance goal factor, $8.998 \%$; task-approach goal factor, $7.314 \%$; other-approach goal factor, $7.058 \%$; self-approach goal factor $6.142 \%$; and other-avoidance goal factor, $5.586 \%$. The component matrix after varimax rotation was employed to identify the items that were more related 
Table 2. Factor loadings, communalities, eigenvalues and percentage of variances for achievement goals

\begin{tabular}{|c|c|c|c|c|c|c|c|c|c|c|c|}
\hline \multirow{2}{*}{ Factor } & \multirow{2}{*}{ Dimensions } & \multirow{2}{*}{ Items } & \multirow{2}{*}{ Communalities } & \multirow{2}{*}{ Eigenvalue } & \multirow{2}{*}{$\begin{array}{c}\% \text { of } \\
\text { Variance }\end{array}$} & \multicolumn{6}{|c|}{ Components } \\
\hline & & & & & & 1 & 2 & 3 & 4 & 5 & 6 \\
\hline \multirow{18}{*}{$\begin{array}{c}\text { Achievement } \\
\text { Goals }\end{array}$} & \multirow{3}{*}{$\begin{array}{c}\text { Task-approach } \\
\text { goal }\end{array}$} & $\mathrm{X} 1$ & .884 & \multirow{3}{*}{1.316} & \multirow{3}{*}{7.314} & & & 859 & & & \\
\hline & & $\mathrm{X} 4$ & .894 & & & & & 848 & & & \\
\hline & & $\mathrm{X9}$ & .898 & & & & & 848 & & & \\
\hline & \multirow{3}{*}{$\begin{array}{c}\text { Task- } \\
\text { avoidance goal }\end{array}$} & $x 6$ & .935 & \multirow{3}{*}{1.620} & \multirow{3}{*}{8.998} & & .852 & & & & \\
\hline & & $\mathrm{X} 8$ & .948 & & & & .853 & & & & \\
\hline & & $\mathrm{X} 10$ & .938 & & & & .857 & & & & \\
\hline & \multirow{3}{*}{$\begin{array}{c}\text { Self-approach } \\
\text { goal }\end{array}$} & $\mathrm{X} 2$ & .926 & \multirow{3}{*}{1.106} & \multirow{3}{*}{6.142} & & & & & .848 & \\
\hline & & $\mathrm{X5}$ & .941 & & & & & & & .848 & \\
\hline & & $\mathrm{X} 11$ & .900 & & & & & & & .805 & \\
\hline & \multirow{3}{*}{$\begin{array}{c}\text { Self- } \\
\text { avoidance goal }\end{array}$} & $\mathrm{X} 3$ & .944 & \multirow{3}{*}{10.085} & \multirow{3}{*}{50.030} & .860 & & & & & \\
\hline & & $\mathrm{X7}$ & .959 & & & .872 & & & & & \\
\hline & & $\mathrm{X} 12$ & .942 & & & .865 & & & & & \\
\hline & \multirow{3}{*}{$\begin{array}{c}\text { Other- } \\
\text { approach goal }\end{array}$} & $\mathrm{X} 13$ & .892 & \multirow{3}{*}{1.270} & \multirow{3}{*}{7.058} & & & & .840 & & \\
\hline & & $\mathrm{X} 14$ & .928 & & & & & & .839 & & \\
\hline & & $\mathrm{X} 15$ & .918 & & & & & & .828 & & \\
\hline & \multirow{3}{*}{$\begin{array}{c}\text { Other- } \\
\text { avoidance goal }\end{array}$} & $\mathrm{X} 16$ & .869 & \multirow{3}{*}{1.005} & \multirow{3}{*}{5.586} & & & & & & .818 \\
\hline & & $\mathrm{X} 17$ & .832 & & & & & & & & .796 \\
\hline & & $\mathrm{X} 18$ & .854 & & & & & & & & .846 \\
\hline
\end{tabular}

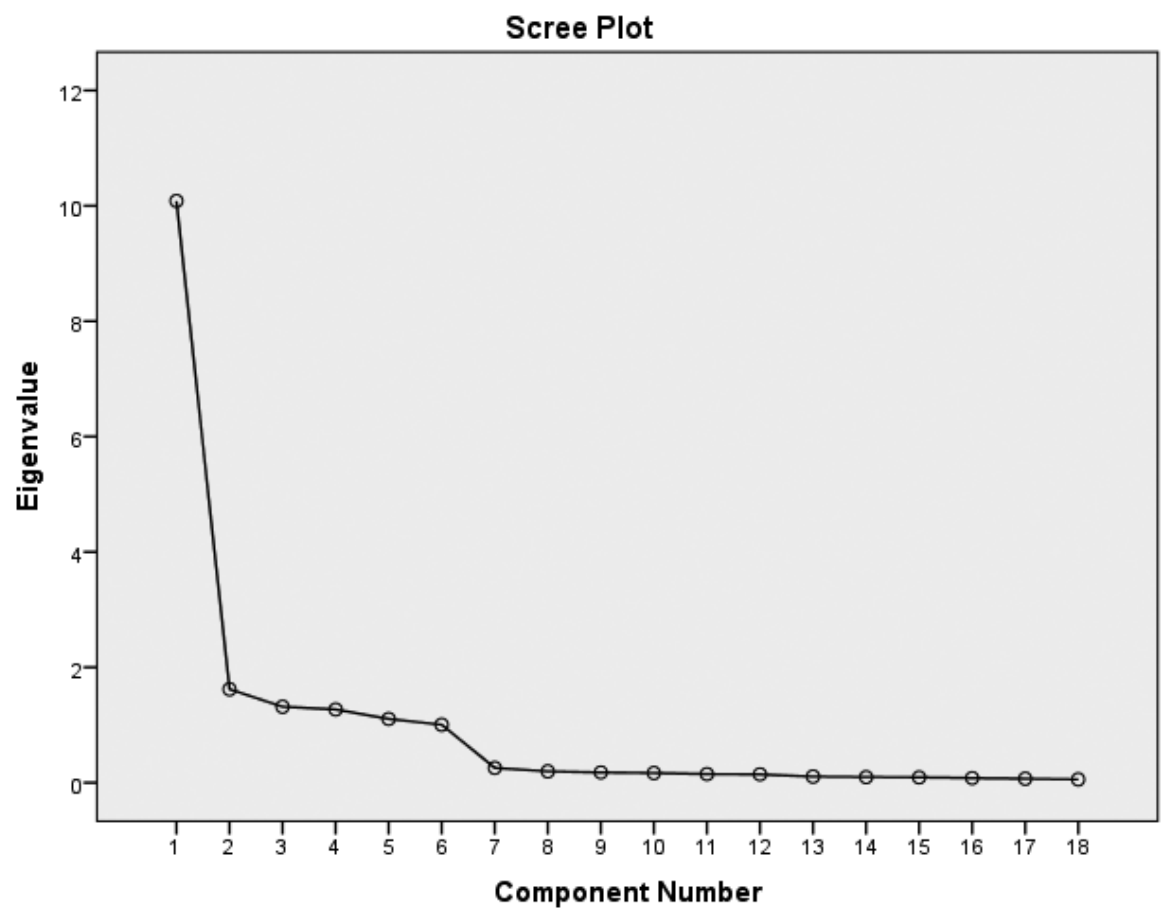

Figure 1. Scree plot of the 18 items for achievement goals

to each factor. In the present study, all suggested 18 items for measuring achievement goals were registered by high loading factors ranging from 0.796 to $0.872(>0.50)$.

Another method to select the correct number of factors to be extracted is to investigate a scree plot (Figure 1). As shown in Figure 1, the scree plot suggests six factors that can be determined.

\section{Confirmatory Factor Analysis: Testing the Measurement Models}

In this study, the EFA suggested a six-factor structure for the achievement goals, which were task-approach goal, task-avoidance goal, self-approach goal, self-avoidance goal, other-approach goal and other-avoidance goal. CFA was conducted to verify the factorial validity of the achievement goals. CFA can provide further evidence regarding the fitness of the suggested model with regard to the structure of the factors identified via EFA. The 
Table 3. Model specifications for the post hoc confirmatory factor analysis

\begin{tabular}{cc}
\hline Parameter & Coefficient \\
\hline$\chi 2$ & 148.213 \\
\hline$\chi^{2} / \mathrm{df}$ & 1.235 \\
\hline $\mathrm{RMSEA}$ & 0.021 \\
\hline $\mathrm{TLI}$ & 0.997 \\
\hline $\mathrm{CFI}$ & 0.998
\end{tabular}

Note. $\chi 2$ : Chi-square goodness of fit; df: Degrees of Freedom; CFI: Comparative Fit Index; TLI: Tucker-Lewis fit index; RMSEA: Root Mean Square Error

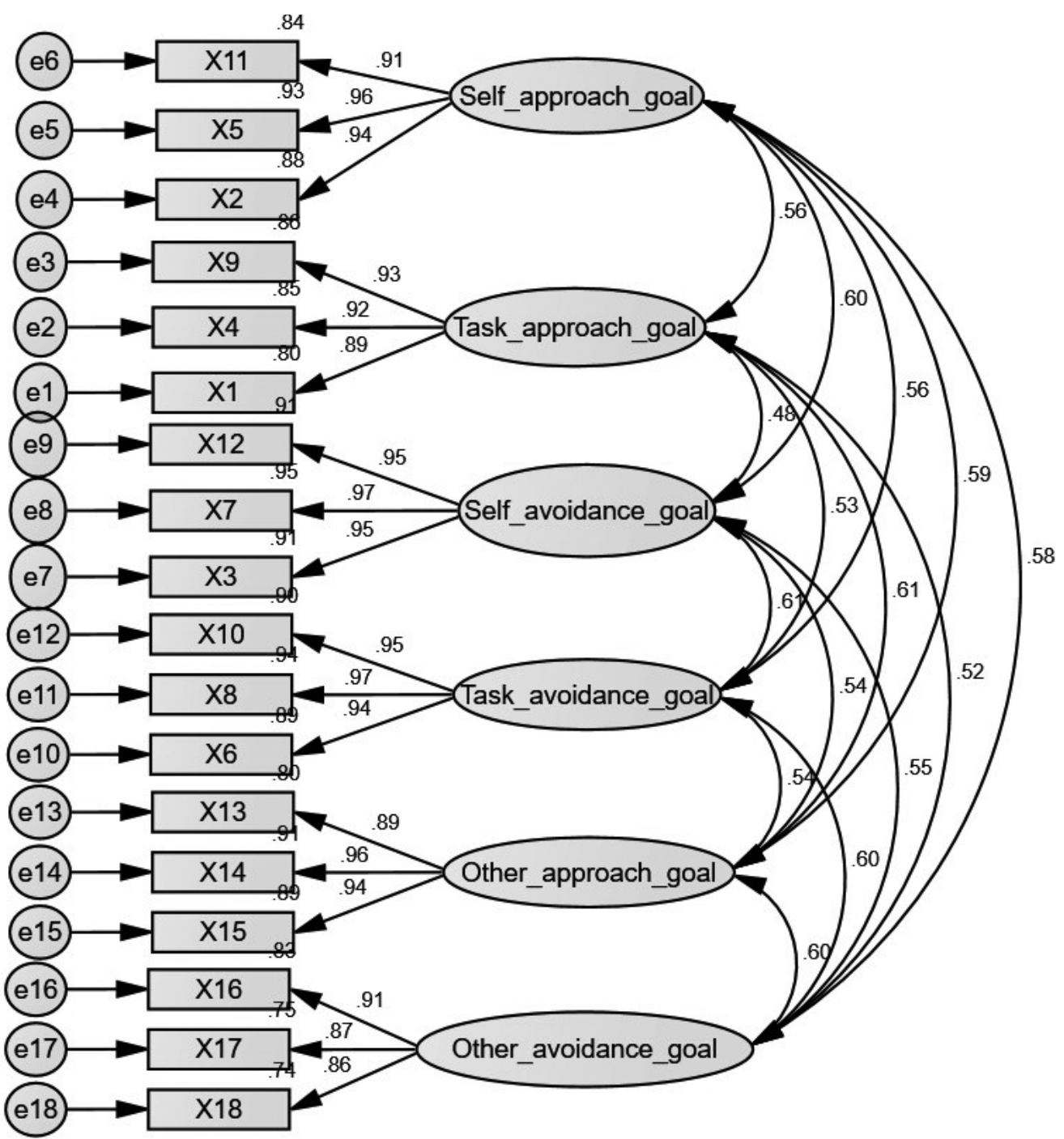

Figure 2. Finalised measurement model of CFA

models were compared using chi-square $\left(\chi^{2}\right)$, CFI, TLI and RMSEA. Table 3 presents the model specifications for the post hoc CFA.

Table 3 shows that the CFA results for the hypothesised six-factor model are excellent. The factor structure achieved acceptable model fit for the Indonesian context. The measurement model of achievement goals in this study indicated acceptable model fit, $\chi^{2}=148.213, \chi^{2} / \mathrm{df}=1.235$, RMSEA $=0.021$, TLI $=0.997$ and CFI $=0.998$. Therefore, the model of CFA presented in Figure 2 is the finalised measurement model that indicated the structure of achievement goals in the Indonesian context.

Figure 2 illustrates that the finalised measurement model of achievement goals differentiates between observed and latent variables. All factor loadings of the six achievement goals' sub-constructs ranged from 0.66 to 0.77 , and the six achievement goals' sub-constructs ranged from 0.87 to 0.97 . Results showed that the factor loadings exceeded the desirable standard of 0.50 (Hair et al., 2010). The finalised model became the baseline model for our next analyses related to cross-validation. 


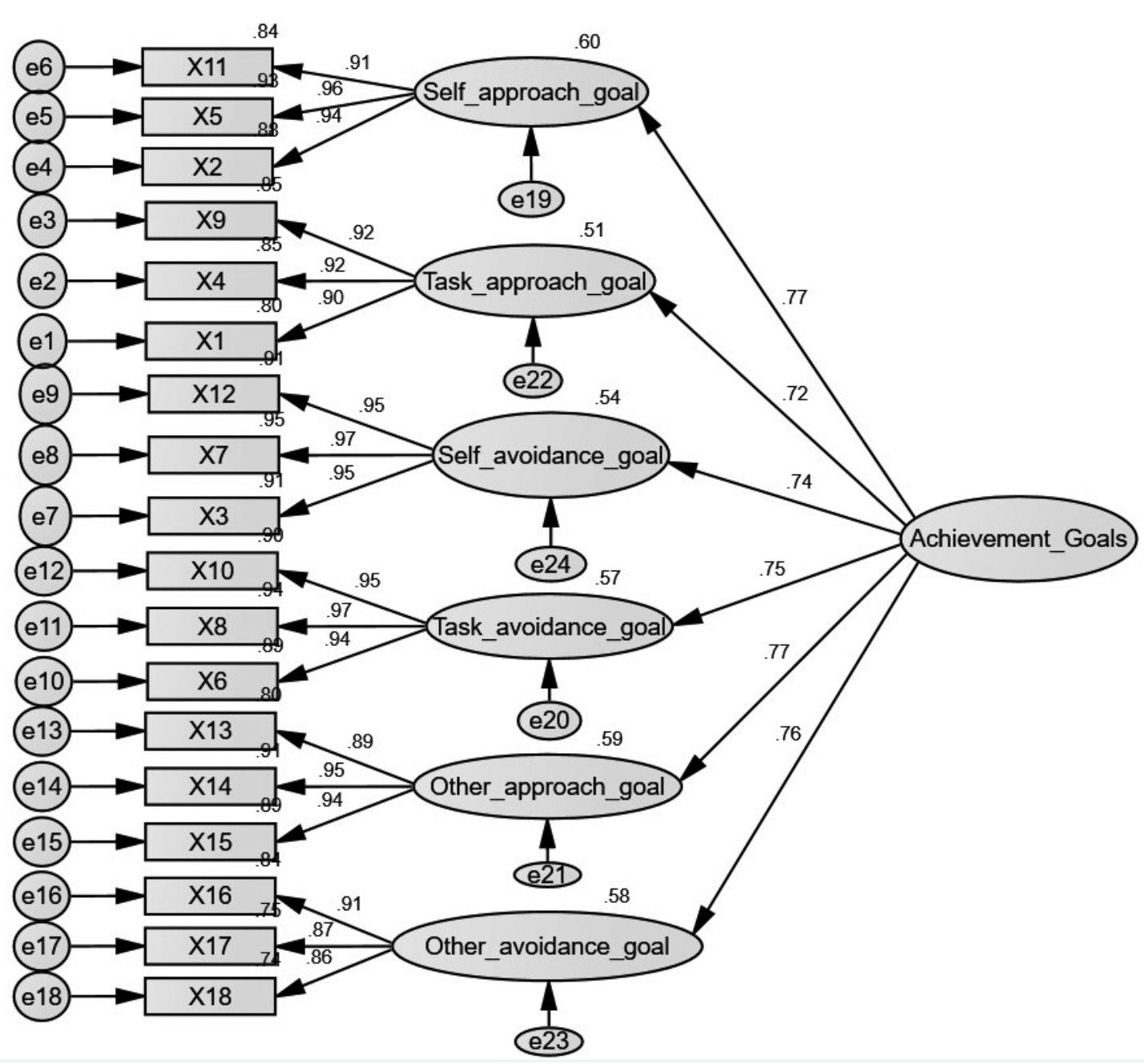

Figure 3. Second-order measurement model for achievement goals

Table 4. Model fit statistics for each hypothesised factor model

\begin{tabular}{cccccc}
\hline Model & $\boldsymbol{\chi}^{\mathbf{2}}$ & $\boldsymbol{\chi}^{\mathbf{2}} / \mathbf{d f}$ & $\mathbf{C F I}$ & $\mathbf{T L I}$ & RMSEA \\
\hline First-order & 148.213 & 1.235 & 0.998 & 0.997 & 0.021 \\
\hline Second-order & 179.830 & 1.394 & 0.996 & 0.995 & 0.027 \\
\hline
\end{tabular}

\section{Confirmatory Factor Analysis: Testing of a Second-order Factor}

A hierarchical factor structure in the current research was also hypothesised and examined. Figure 3 illustrates the results of the hypothesised second-order factorial structure for achievement goals.

Although both models resulted in different values, Figure 3 shows that a second-order measurement model for achievement goals met the criteria for good fitting models. The path coefficients for achievement goals varied among sub-constructs: task-approach goal (0.72), task-avoidance goal (0.75), self-approach goal (0.77), selfavoidance goal (0.74), other-approach goal (0.77) and other-avoidance goal (0.76). A second-order measurement model for achievement goals also indicated acceptable model fit, $\chi^{2}=179.830, \chi^{2} / \mathrm{df}=1.394$, RMSEA $=0.027, \mathrm{TLI}=$ 0.995 and CFI $=0.996$. Table 4 lists the model fit statistics comparing the first- and second-order measurement models for achievement goals.

\section{Reliability of the Achievement Goal Scales}

Reliability means the stability and consistency of the scores obtained (Creswell, 2012; Fraenkel \& Wallen, 2009). Scores should be almost identical when researchers administer the instrument multiple times at different periods. In the current study, degree of internal consistency or reliability, construct reliability (CR) and AVE were calculated. A measure of reliability as internal consistency is the Cronbach's alpha, frequently referred to as the alpha 
Table 5. Reliability analysis for achievement goals

\begin{tabular}{|c|c|c|c|c|c|}
\hline Construct & Sub-Construct & Alpha Value & $\begin{array}{c}\text { Overall Cronbach's } \\
\text { Alpha }\end{array}$ & CR & AVE \\
\hline \multirow{6}{*}{ Achievement Goals } & Task-approach goal & 0.938 & \multirow{6}{*}{0.953} & 0.939 & 0.836 \\
\hline & Task-avoidance goal & 0.968 & & 0.968 & 0.910 \\
\hline & Self-approach goal & 0.956 & & 0.957 & 0.882 \\
\hline & Self-avoidance goal & 0.972 & & 0.973 & 0.922 \\
\hline & Other-approach goal & 0.951 & & 0.952 & 0.868 \\
\hline & Other-avoidance goal & 0.911 & & 0.911 & 0.774 \\
\hline
\end{tabular}

coefficient of reliability, or simply the alpha (Cohen, Manion, \& Morrison, 2007). Acceptable values of Cronbach's alpha range from 0.80 and above (Lim, 2007) , CR should be more than 0.60 and AVE must be over 0.50 (Awang, 2012). Table 5 enumerates the Cronbach's alpha, CR and AVE explained by the sub-constructs of achievement goals.

Table 5 lists the Cronbach's alpha, overall Cronbach's alpha, CR and AVE for the latent variables. The reliability values of some scales exceeded the desirable standard of 0.70: task-approach goal, $a=0.938$; task-avoidance goal, a $=0.968$; self-approach goal, $a=0.956$; self-avoidance goal, $a=0.972$; other-approach goal, $a=0.951$; and otheravoidance goal, $a=0.911$. Cronbach's alpha reliability coefficient was found to be 0.953 for the entire sub-construct. At the same time, all the CR values for the sub-constructs of achievement goals exceeded the desirable standard of 0.60, which indicated high internal consistency. Moreover, the AVE for the six latent variables exceeded the common cut-off value of 0.50 , demonstrating that this study had acceptable discriminant validity.

\section{DISCUSSION}

This study examined a reliable and valid instrument of achievement goals for Indonesian students in mathematics education programmes. EFA indicated that the students' data involved a six-factor structure: taskapproach goal, task-avoidance goal, self-approach goal, self-avoidance goal, other-approach goal and otheravoidance goal. The structure also conforms to the original six-factor structure of the achievement goals. Although task- and self-based goals are regarded under a single concept of mastery goal, the disparity between task-based goals and self-based goals in this research is relevant to the mathematics education field. The findings of this work are consistent with those of prior research (Brondino et al., 2014; David, 2012; Lower \& Turner, 2016; Mascret et al., 2015, 2017; Méndez-Giménez et al., 2017; Wu, 2012). The present research also employs the framework of Elliot et al. (2011), which involves task-based goals, self-based goals and other-based goals. We deduced that the similarities of this research and the prior study on the sub-constructs of achievement goals arise from having samples from the higher education level, which entail complex thinking. Additionally, differences in cultural backgrounds are not only limited to how strongly students have distinct perceptions, but also to what the absolute perception constructs are (Bofah \& Hannula, 2015).

The CFA approach also confirmed the suitability of the questionnaire for measuring achievement goals. This outcome coincides with the findings of Elliot et al. (2011) that indicated the hypothesised $3 \times 2$ model fit the data better than the $2 \times 2$ model, the trichotomous model and the dichotomous model when examined for undergraduates students in the United States. The results offer further evidence that the generally accepted achievement goal instruments are truly universal. Hence, the Indonesian version of the $3 \times 2$ achievement goal questionnaire may be employed to measure students in mathematics education programmes in Indonesia. The reliabilities of achievement goals for the Indonesian sample were largely acceptable as well. However, the hypothesis about a reliable and valid achievement goal instrument for elementary and secondary school students in Indonesia must be tested in future research because prior studies presented inconsistent findings on its validity and reliability for elementary and secondary school students in Taiwan.

In addition to examining the validity and reliability of a $3 \times 2$ achievement goal scale for mathematics education programmes, the present study sought to determine the nature of students' achievement goals in such programmes in Indonesia. Our study revealed that Indonesian students in mathematics education programmes generally improved via the factors of other-avoidance goal and self-approach goal. Note that Indonesian students reported greater levels of self-based goals and other-based goals than task-based goals. Surprisingly, Indonesian students in mathematics education programmes are more likely to employ other-avoidance and self-approach goals for their competence. Avoidance-based goals are based on failure or on evading this negative possibility, whereas approachbased goals are based on success and maintaining positive possibility. We may infer that students who utilise otheravoidance goals often avoid doing worse than their counterparts, while those who utilise self-approach goals also focus on the attainment of self-based competence (perform better than before). The results of the current study are also consistent with prior research (David, 2012; Liem \& Nie, 2008), which found that Indonesian students tend to adopt social-oriented achievement motivation and performance-approach and mastery-avoidance goals. Similarly, 
first-year undergraduate students in the Philippines take a self-based and other-based standard for the assessment of their competence. Possible reasons include social perceptions, social affiliation and social approval, all of which mediate achievement goals (Bernardo \& Ismail, 2010). These results highlight the importance of preserving achievement goals for Indonesian students in mathematics education programmes in terms of enhancing their learning outcomes by encouraging task-based and self-based goals rather than other-based goals.

\section{CONCLUSION AND RECOMMENDATIONS}

This research finds that the achievement goals of Indonesian students in mathematics education programmes comprise a six-factor structure: task-approach goal, task-avoidance goal, self-approach goal, self-avoidance goal, other-approach goal and other-avoidance goal. The analyses confirm that task-based goals, self-based goals and other-based goals can be a worthwhile scale for measuring achievement goals in the Indonesian context. The reliabilities of achievement goals for the Indonesian sample are also generally acceptable. Both the differences and similarities found between the current and previous studies are indicative of dramatic cultural diversity. In addition, to determine the achievement goals of students' mathematics education programmes seem to be more important for researchers and teachers in Indonesia in term of gaining the quality of mathematics education. Students participating actively in the teaching and learning process will be determined with their goals. Teachers can present a suitable learning strategy to enhance the mathematical proficiency of students by considering their goals on mathematics. Moreover, the finding of the current research will also contribute to the Ministry of Education in Indonesia with current data that would aid the ministry in making better policy decisions and applying educational strategies with greater certainty the implementation of curriculum in University.

This study suggests the importance of validating the structure of pupils' achievement goals by using EFA and confirming it through CFA rather than translating a construct into a different language. This recommendation is attributed to the progressively noticeable differences in cultural backgrounds. In addition, the hypothesis about a reliable and a valid achievement goal instrument for elementary and secondary school students in Indonesia must be tested in the future because previous research presented inconsistent findings of validity and reliability for elementary and secondary school students in Taiwan. Other factors, such as socioeconomics issues or level of achievement, should likewise be investigated further.

\section{REFERENCES}

Ames, C. (1992). Classrooms: Goals, structures, and student motivation. Journal of Educational Psychology, 84(3), 261271. https:// doi.org/10.1037/0022-0663.84.3.261

Ames, C., \& Archer, J. (1988). Achievement goals in the classroom: Students' learning strategies and motivation processes. Journal of Educational Psychology, 80(3), 260-267. https:/ / doi.org/10.1037/0022-0663.80.3.260

Awang, Z. (2012). Structural Equation Modeling Using Amos Graphic. Shah Alam: UiTM Press.

Barron, K. E., \& Harackiewicz, J. M. (2001). Achievement goals and optimal motivation: testing multiple goal models. Journal of Personality and Social Psychology, 80(5), 706-722. https://doi.org/10.1037/00223514.80.5.706

Bernardo, A. B. I., \& Ismail, R. (2010). Social perceptions of achieving students and achievement goals of students in Malaysia and the Philippines. Social Psychology of Education, 13, 385-407. https:/ / doi.org/10.1007/s11218010-9118-y

Bofah, E. A., \& Hannula, M. S. (2015). Studying the factorial structure of Ghanaian twelfth-grade students' views on mathematics. In B. Pepin \& Roesken-Winter (Eds.), From beliefs to dynamic affect systems in mathematics education (pp. 355- 381). Cham, Switzerland: Springer International Publishing. https:/ / doi.org/10.1007/978-3-319-06808-4

Brondino, M., Raccanello, D., \& Pasini, M. (2014). Achievement goals as antecedents of achievement emotions: The $3 \times 2$ achievement goal model as a framework for learning environments design. In T. Mascio, R. Gennari, P. Vitorini, R. Vicari, \& F. de la Prieta (Eds.), Methodologies and Intelligent Systems for Technology Enhanced Learning. Advances in Intelligent Systems and Computing (pp. 53-60). Switzerland: Springer, Cham. https://doi.org/10.1007/978-3-319-07698-0_7

Chamberlin, S. A. (2010). A review of instruments created to assess affect in mathematics. Journal of Mathematics Education, 3(1), 167-182.

Chen, W.-W. (2015). The relations between filial piety, goal orientations and academic achievement in Hong Kong. Educational Psychology, 36(5), 898-915. https:/ / doi.org/10.1080/01443410.2015.1008404

Chua, Y. P. (2014). Ujian Regresi, Analisis Faktor, dan Analisis SEM. Shah Alam: McGraw Hill Education. 
Clarke, D. J. (2013). Contingent conceptions of accomplished practice: The cultural specificity of discourse in and about the mathematics classroom. ZDM Mathematics Education, 45, 21-33. https:// doi.org/10.1007/s11858012-0452-8

Cohen, L., Manion, L., \& Morrison, K. (2005). Research methods in education. Research Methods in Education. London and New York: RoutledgeFalmer. https:/ / doi.org/10.1080/19415257.2011.643130

Cohen, L., Manion, L., \& Morrison, K. (2007). Research Methods in Education. New York: Routledge. https:/ / doi.org/10.4324/9780203029053

Creswell, J. W. (2012). Educational research: Planning, conducting, and evaluating quantitative and qualitative research. Educational Research (Vol. 4). Cambridge: Pearson. https:/ / doi.org/10.1017/CBO9781107415324.004

Creswell, J. W. (2014). Research Design: Qualitative, Quantitative, and Mixed Methods Approaches. California: SAGE Publications, Inc.

David, A. (2012). Structural validation of the $3 \times 2$ achievement goal model. Educational Measurement and Evaluation Review, 103(3), 50-59. https:// doi.org/10.1037/a0023952

Dweck, C. S. (1986). Motivational processes affecting learning. American Psychologist, 41(10), 1040-1048. https:/ / doi.org/10.1037/0003-066X.41.10.1040

Dweck, C. S., \& Leggett, E. L. (1988). A social cognitive approach to motivation and personality. Psychological Review, 95(2), 256-273. https:/ / doi.org/10.1037/0033-295X.95.2.256

Elliot, A. J. (1999). Approach and avoidance motivation and achievement goals. Educational Psychologist, 34(3), 169189. https://doi.org/10.1207/s15326985ep3403_3

Elliot, A. J., \& Church, M. A. (1997). A hierarchical model of approach and avoidance achievement motivation. Journal of Personality and Social Psychology, 72(1), 218-232. https:/ / doi.org/10.1037/ /0022-3514.72.1.218

Elliot, A. J., \& Harackiewicz, J. M. (1996). Approach and avoidance achievement goals and intrinsic motivation: A mediational analysis. Journal of Personality and Social Psychology, 70(3), 461-475. https:/ / doi.org/10.1037/0022-3514.70.3.461

Elliot, A. J., \& McGregor, H. A. (2001). A 2 × 2 achievement goal framework. Journal of Personality and Social Psychology, 80(3), 501-519. https:/ / doi.org/10.1037/0022-3514.80.3.501

Elliot, A. J., Murayama, K., \& Pekrun, R. (2011). A $3 \times 2$ achievement goal model. Journal of Educational Psychology, 103(3), 632-648. https:/ / doi.org/10.1037/a0023952

Fitzgerald, S. M., Rumrill, P. D., \& Schenker, J. D. (2004). Perspectives on scientific inquiry causal-comparative research designs. Journal of Vocational Rehabilitation, 20, 143-150.

Fraenkel, J. R., \& Wallen, N. E. (2009). How to Design and Evaluate Research in Education. New York: McGraw-Hill.

Frohlich, M. T., \& Westbrook, R. (2001). Arcs of integration: An international study of supply chain strategies. Journal of Operations Management, 19, 185-200. https:/ / doi.org/10.1016/S0272-6963(00)00055-3

Gillet, N., Lafrenière, M. A. K., Huyghebaert, T., \& Fouquereau, E. (2015). Autonomous and controlled reasons underlying achievement goals: Implications for the $3 \times 2$ achievement goal model in educational and work settings. Motivation and Emotion, 39(6), 858-875. https:/ / doi.org/10.1007/s11031-015-9505-y

Hair, J. F., Black, B. ., Babin, B. J., Anderson, R. E., \& Tatham, R. L. (2006). Multivariate Data Analysis 6th Edition. Pearson International Edition.

Hair, J. F., Black, W. C., Babin, B. J., \& Anderson, R. E. (2010). Multivariate Data Analysis (7th Edition). Englewood Cliffs, NJ: Prentice Hall. https:/ / doi.org/10.1016/j.jmva.2009.12.014

Harackiewicz, J. M. J., Barron, K. E., \& Elliot, A. J. (1998). Rethinking achievement goals: When are They adaptive for college students and why? Educational Psychologist, 33(1), 1-21. https://doi.org/10.1207/s15326985ep3301

Kline, R. B. (2005). Principles and practice of structural equation modeling. New York: The Guilford Press.

Langer, M. (2012). Das $3 \times 2$ Achievement Goal Model: Konsequenzen für Fähigkeitsselbstkonzept, Umgang mit Misserfolg und Interesse. Universitat Wien.

Liem, A. D., \& Nie, Y. (2008). Values, achievement goals, and individual-oriented and social-oriented achievement motivations among Chinese and Indonesian secondary school students. International Journal of Psychology, 43(5), 898-903. https: / / doi.org/10.1080/00207590701838097

Lim, C. (2007). Penyelidikan Pendidikan. Pendekatan Kuantitatif dan Kualitatif. Kuala Lumpur: McGraw Hill Education.

Lower, L. M., \& Turner, B. A. (2016). Examination of the 3×2 achievement goal model in collegiate recreation: Comparison across Sport programs. Journal of Amateur Sport, 2(2), 75-102. https://doi.org/10.17161/jas.v0i0.5689 
Lower, L. M., Newman, T. J., \& Pollard, W. S. (2016). Examination of the 3x2 achievement goal model in recreational sport: Associations with perceived benefits of sport participation. International Journal of Sport Management, Recreation \& Tourism, 26, 44-53. https:/ / doi.org/10.5199/ijsmart-1791-874X-26c

Maehr, M. L., \& Zusho, A. (2009). Achievement goal theory: The past, present, and future. Handbook of Motivation at School, 77-104.

Maretasani, L. D., Masrukan, M., \& Dwijanto, D. (2016). Problem solving ability and metacognition based goal orientation on problem based learning. In S. Saptono, Masturi, A. Purwinarko, \& D. Alighiri (Eds.), International Conference on Mathematics, Science, and Education 2016 (ICMSE 2016) Problem (pp. 26-30). Semarang: Faculty of Mathematics and Natural Sciences Semarang State University.

Mascret, N., Elliot, A. J., \& Cury, F. (2015). Extending the 3x2 achievement goal model to the sport domain: The 3x2 achievement goal questionnaire for sport. Psychology of Sport and Exercise, 17, 7-14. https://doi.org/10.1016/j.psychsport.2014.11.001

Mascret, N., Elliot, A. J., \& Cury, F. (2017). The $3 \times 2$ achievement goal questionnaire for teachers. An International Journal of Experimental Educational Psychology, 37(3). https:/ / doi.org/10.1080/01443410.2015.1096324

Méndez-Giménez, A., Cecchini-Estrada, J.-A., Fernández-Río, J., Saborit, J. A. P., \& Méndez-Alonso, D. (2017). 3x2 classroom goal structures, motivational regulations, self-concept, and affectivity in secondary school. The Spanish Journal of Psychology, 20. https:/ / doi.org/10.1017/sjp.2017.37

Midgley, C., Kaplan, A., \& Middleton, M. (2001). Performance-approach goals: Good for what, for whom, under what circumstances, and at what cost? Journal of Educational Psychology, 93(1), 77-86. https:/ / doi.org/10.1037/0022-0663.93.1.77

Nicholls, J. G. (1984). Achievement motivation: Conceptions of ability, subjective experience, task choice, and performance. Psychological Review, 91(3), 328-346. https:/ / doi.org/10.1037/0033-295X.91.3.328

Pintrich, P. (2000). An achievement goal theory perspective on issues in motivation terminology, theory, and research. Contemporary Educational Psychology, 25(1), 92-104. https:/ / doi.org/10.1006/ceps.1999.1017

Pulkka, A., \& Niemivirta, M. (2015). The relationships between adult students' achievement goal orientations, selfdefined course goals, course evaluations, and performance. Journal for Educational Research Online, 7(3), 2853.

Schumacker, R. E., \& Lomax, R. G. (2010). Structural Equation Modeling: Third Edition. New York: Taylor \& Francis Group.

Stoeber, J., Haskew, A. E., \& Scott, C. (2015). Perfectionism and exam performance: The mediating effect of taskapproach goals. Personality and Individual Differences, 74, 171-176. https://doi.org/10.1016/j.paid.2014.10.016

Treasure, D. C., \& Roberts, G. C. (1995). Applications of achievement goal theory to physical education: Implications for enhancing motivation. Quest, 47, 475-489. https:/ / doi.org/10.1080/00336297.1995.10484170

Witkow, M. R., \& Fuligni, A. J. (2007). Achievement goals and daily school experiences among adolescents with Asian, Latino, and European American backgrounds. Journal of Educational Psychology, 99(3), 584-596. https:/ / doi.org/10.1037/0022-0663.99.3.584

Wu, C.-C. (2012). The cross-cultural examination of $3 \times 2$ achievement goal model in Taiwan. Procedia-Social and Behavioral Sciences, 69, 422-427. https:// doi.org/10.1016/j.sbspro.2012.11.429

Wynne, H. M. (2014). Integrating the demonstration orientation and standards-based models of achievement goal theory. Fordham University. Retrieved from http://ezproxy.um.edu.my:2048/login?url= http:/ / search.proquest.com/ docview / 1498130571?accountid=28930

Yang, Y., Taylor, J., \& Cao, L. (2016). The $3 \times 2$ achievement goal model in predicting online student test anxiety and help-seeking. International Journal of E-Learning \& Distance Education, 32(1), 1-16.

\section{http://www.ejmste.com}

